\title{
Sintesis Dan Karakterisasi Bioplastik Berbasis Pati Sagu- Kitosan Berisi Pelepah Sawit Dan Plastizier Gliserol
}

\author{
Yuli Andriani' ${ }^{1}$, Rahmadini Syafri ${ }^{2,}$, , Wirdati Irma ${ }^{3}$, Prima Yane Putri ${ }^{4}$, Annisa \\ Nadia Putri, ${ }^{5}$, Siti Nuriana ${ }^{6}$, Diar Veronika ${ }^{7}$ \\ 1,2,4,5,6,7 Chemistry Departments, Mathematics, Science and Health Faculty, Universitas Muhammadiyah \\ Riau, Pekanbaru, Indonesia \\ ${ }^{3}$ Biology Departments, Mathematics, Science and Health Faculty, Universitas Muhammadiyah Riau, \\ Pekanbaru, Indonesia \\ *Correspondence emails: rahmadini@umri.ac.id
}

\begin{abstract}
Bioplastic or biodegradable plastic is an alternative to conventional plastic that is harmful to the environment. Biodegradable plastics have the same uses as synthetic plastics but are friendly to the environment because of their properties that can be decomposed by the activity of decomposing microorganisms. Chitosan is used as a biopolymer to improve its mechanical properties because it can form hydrogen bonds between chains with amylose and amylopectin in starch. One of the basic ingredients of biodegerdable plastic is starch. Starch is one of the most widely distributed polysaccharides in nature. Chitosan has amine functional groups, primary and secondary hydroxyl groups. The presence of these functional groups causes chitosan to have high chemical reactivity because it can form hydrogen bonds, so chitosan is an ideal mixing material. In addition, chitosan is the most abundant chitin derivative on earth after cellulose, is hydrophobic and can form good sheets and membranes. This research focuses more on the effect of adding cellulose from palm midrib fiber to the bioplastic characteristics of sago-chitosan starch with the addition of glycerol plasticizer. The purpose of this study was to determine the best variation of sago-chitosan starch bioplastic with palm midrib fiber filler and glycerol plasticizer which was optimal for the characteristics of the resulting bioplastic with several parameters, namely tensile strength test, biodegradation test, analysis of functional groups in bioplastics using the FTIR instrument ( Fourier Transform-Infra Red), Scanning Electron Microscopy (SEM) and water resistance test.
\end{abstract}

Keywords: Bioplastic, sago starch, chitosan, cellulose, glycerol

\begin{abstract}
Abstrak
Bioplastik atau plastik biodegradble merupakan salah satu alternatif pengganti plastik konvesional yang membahayakan bagi lingkungan. Plastik biodegradable memiliki kegunaan yang sama dengan plastik sintetik tetapi ramah terhadap lingkungan karena sifatnya yang dapat terurai oleh aktivitas mikroorganisme pengurai. Kitosan digunakan sebagai biopolimer untuk meningkatkan sifat mekanik karena dapat membentuk ikatan hidrogen antar rantai dengan amilosa dan amilopektin pada pati. Salah satu bahan dasar plastik biodegerdable yaitu pati. Pati adalah salah satu jenis polisakarida yang amat luas tersebar dialam. Kitosan memiliki gugus fungsi amin, gugus hidroksil primer dan sekunder. Keberadaan gugus fungsi tersebut mengakibatkan kitosan memiliki kereaktifan kimia yang tinggi karena dapat membentuk ikatan hidrogen,
\end{abstract}

Received: November 2021, Accepted : November 2021 - Jurnal Photon Vol.12 No.1

DOI : https://doi.org/10.37859/jp.v12i1.3359

PHOTON is licensed under a Creative Commons Attribution-ShareAlike 4.0 International License 
http://ejurnal.umri.ac.id/index.php

sehingga kitosan merupakan bahan pencampur yang ideal. Selain itu kitosan merupakan turunan kitin yang paling banyak di bumi setelah selulosa, bersifat hidrofobik serta dapat membentuk lembaran dan membran yang baik. penelitian ini yang lebih berfokus pada pengaruh penambahan selulosa dari serat pelepah sawit terhadap karakteristik bioplastik dari pati sagu- kitosan dengan penambahan plasticizer gliserol. Tujuan dari penelitian ini untuk mengetahui variasi terbaik bioplastik pati sagu-kitosan dengan pengisi serat pelepah kelapa sawit dan plasticizer gliserol yang optimum terhadap karakteristik bioplastik yang dihasilkan dengan beberapa parameter yaitu uji kuat tarik, uji biodegradasi, analisis gugus fungsi pada bioplastik menggunakan alat instrument FTIR (Fourier Transform-Infra Red), Scaning Electron Microscopy (SEM) dan uji ketahanan air.

Kata kunci: Bioplastik, pati sagu, kitosa, selulosa, gliserol

\section{Introduction}

Bioplastik atau plastik biodegradable merupakan salah satu alternatif pengganti plastik konvesional yang membahayakan bagi lingkungan (Novriyani, 2019). Plastik biodegradable memiliki kegunaan yang sama dengan plastik sintetik tetapi ramah terhadap lingkungan karena sifatnya yang dapat terurai oleh aktivitas mikroorganisme pengurai. Plastik biodegradable adalah material polimeryang mempunyai berat molekul yang rendah yang hampir seluruh komponen penyusunnya berasal dari bahan dari alam yang dapat diperbaharui. Salah satu bahan alam yang dapat digunakan sebagai bahan baku plastik biodegradable adalah pati yang berasal dari sagu (Said, 2018).

Salah satu bahan dasar plastik biodegerdable yaitu pati. Pati adalah salah satu jenis polisakarida yang amat luas tersebar dialam. Pati disimpan sebagai cadangan makanan bagi tumbuhan di dalam biji (padi, jagung), didalam umbi (ubikayu, ubi jalar, dan pada batang (sagu, aren). Tanaman sagu termasuk dalam keluarga Palmae dari genus Metroxylon. Potensi tanaman sagu terutaman di wilayah Sulawesi Tenggara mencapai 5.912 Hektar yang berpusat pada Kecamatan Angata Kabupaten Konawe Selatan, Kecamatan Soropia Kabupaten Konawe dan Kecamatan Puuwatu Kota Kendari (Muhidin, 2012). Dengan komposisi pati sagu sebesar 75,88\% sangat baik untuk digunakan sebagai bahan utama pembuatan plastik biodegradable. Penelitian yang dilakukan oleh Yuniarti (2014) dengan mensintesis dan memodifikasi bioplastik berbahan pati sagu dengan asam asetat dan gliserol menghasilkan bioplastik yang dapat terdegradasi secara alami dengan media pasir dan miroba EM4 selama 24 hari. Dilihat dari potensi sagu di Sulawesi Tenggara yang melimpah dan dari hasil penelitian yang telah dilakukan, maka peneliti menggunakan sagu sebagai sumber pati bahan bakupembuatan plastik biodegradable.

Kitosan digunakan sebagai biopolimer untuk meningkatkan sifat mekanik karena dapat membentuk ikatan hidrogen antar rantai dengan amilosa dan amilopektin pada pati. Kitosan memiliki gugus fungsi amin, gugus hidroksil primer dan sekunder. Keberadaan gugus fungsi tersebut mengakibatkan kitosan memiliki kereaktifan kimia yang tinggi karena dapat membentuk ikatan hidrogen, sehingga kitosan merupakan bahan pencampur yang ideal. Selain itu kitosan merupakan turunan kitin yang paling banyak di bumi setelah selulosa, bersifat hidrofobik serta dapat membentuk lembaran dan membran yang baik.

Received: November 2021, Accepted : November 2021 - Jurnal Photon Vol.12 No.1

DOI : https://doi.org/10.37859/jp.v12i1.3359

PHOTON is licensed under a Creative Commons Attribution-ShareAlike 4.0 International License 


\section{http://ejurnal.umri.ac.id/index.php}

Dari hasil penelitian yang dilakukan oleh Pamilia Coniwanti (2014) kitosan dapat meningkatkan nilai kuat tarik film plastik biodegradable dari bahan pati jagung, selanjutnya semakin tinggi konsentrasi kitosan akan menyebabkan rongga-rongga film plastik semakin sedikit yang akan memperkuat film plastik. Pemberian kitosan akan meningkatkan ketahanan air dari film plastik biodegradable, kemudian dengan penambahan jumlah konsentrasi dari kitosan akan meningkatkan kemampuan degradasi film plastik dalam tanah (Said, 2018). Beberapa pengembangan bioplastik menggunakan bahan-bahan alam yang mengandung pati dan selulosa alami. Kedua bahan tersebut dikompositkan dan dilakukan perbandingan perlakuan untuk mengetahui karakterisasi dan fisikokimiawi komposit film tersebut memperbaiki sifat fisik dan mekanik plastik (Septiosari et al. 2014). Dengan pemanfaatan selulosa dari pelepah kelapa sawit sebagai filler pada pembuatan bioplastik untuk memperkuat fisik dari bioplastik yang dihasilkan dari selulosa (Rasli, 2017).

Berdasarkan latar belakang dan referensi penelitian sebelumnya diatas, maka dilakukanlah penelitian ini yang lebih berfokus pada pengaruh penambahan selulosa dari serat pelepah sawit terhadap karakteristik bioplastik dari pati sagu- kitosan dengan penambahan plasticizer gliserol. Tujuan dari penelitian ini untuk mengetahui variasi terbaik bioplastik pati sagu-kitosan dengan pengisi serat pelepah kelapa sawit dan plasticizer gliserol yang optimum terhadap karakteristik bioplastik yang dihasilkan dengan beberapa parameter yaitu uji kuat tarik, uji biodegradasi, analisis gugus fungsi pada bioplastik menggunakan alat instrument FTIR (Fourier Transform-Infra Red), Scaning Electron Microscopy (SEM) dan uji ketahanan air.

\section{The Methods}

\subsection{Alat/Bahan/Material}

Alat yang digunakan dalam penelitian ini diantaranya alat - alat gelas, hotplate stirrer, oven, desikator, neraca, cawan petri, Fourier Transform Infrared Spectroscopy (FTIR) dan Scanning Microscop Electron (SEM). Bahan-bahan yang digunakan pati sagu, kitosa, gliserol, selulosa, asam asetat, natrium hipoklorit, dan aqua DM. Bahan yang digunakan diperoleh dari Kabupaten di Provinsi Riau, Laboratorium Kimia Universitas Muhammadiyah Riau dan Laboratorium Kimia Fisik Universitas Riau.

\subsection{Prosedur Penelitian}

\subsubsection{Pembuatan Pati Sagu}

Sagu ditambahkan air dengan perbandingan 500 gr sagu dan $250 \mathrm{ml}$ air. Kemudian disaring dengan menggunakan kain kasa sampai diperoleh ampas dan filtrat. Selanjutnya filtrat pati yang diperoleh dimasukkan ke dalam wadah plastik dan diendapkan filtratnya selama 24 jam. Setelah 24 jam terbentuk dua lapisan yaitu lapisan air dan endapan pati. Air hasil endapan dibuang sehingga diperoleh endapan pati basah. Selanjutnya dicuci kembali dengan air sampai air cucian jernih kemudian diendapkan lagi sampai diperoleh endapan pati yang bersih.Kemudian pati dikeringkan dengan cara menjemurnya di bawah sinar matahari selama 2 hari untuk mendapatkan pati kering lalu dihaluskan dengan menggunakan soft belender sampai halus selanjutnya diayak dengan menggunakan ayakan dengan 100 mesh.

Received: November 2021, Accepted : November 2021 - Jurnal Photon Vol.12 No.1

DOI : https://doi.org/10.37859/jp.v12i1.3359

PHOTON is licensed under a Creative Commons Attribution-ShareAlike 4.0 International License 


\section{http://ejurnal.umri.ac.id/index.php}

\subsubsection{Penyediaan Larutan Kitosan}

Larutan kitosan 3\% dibuat dengan cara menimbang sebanyak 3 gramkitosan dan dimasukkan ke dalam beaker glass $250 \mathrm{ml}$. Selanjutnya dilarutkan dengan asam asetat $1 \%$ sampai volume $100 \mathrm{ml}$, kemudian diaduk menggunakan magnetic stirrer selama 25 menit dengan cara pemanasan diatas hot plate pada suhu $80^{\circ} \mathrm{C}$ sampai terbentuk larutan homogen dan membentuk larutan kental.Perlakuan pembuatan larutan kitosan diulangi untuk konsentrasi 4\% dan 5\%.

\subsubsection{Penyediaan Serat Pepelah Sawit}

Sampel pelepah kelapa sawit sebanyak 50 gram ditambahkan 1000 mlnatrium hidroksida 4\% (b/v) pada suhu $70^{\circ} \mathrm{C}$ selama $2 \mathrm{jam}$. Kemudian dicuci dengan aquades sampai pH netral. Setelah itu dilakukan proses pemutihan dengan menggunakan $1000 \mathrm{ml}$ natrium hipoklorit $1,7 \%\left(\mathrm{v} / \mathrm{v}\right.$ ) pada suhu $70^{\circ} \mathrm{C}$ selama 4 jam. Kemudian dicuci dengan aquades sampai pH netral.Kemudian dikeringkan dalam oven pada suhu $70^{\circ} \mathrm{C}$ selama 8 jam. Kemudian dihaluskan menggunakan blender. Sehingga diperoleh serbuk kering selulosa.

\subsubsection{Pembuatan Plastik Biodegredable}

Pada pembuatan bioplastik variasi yang dilakukan adalah penambahanlarutan kitosan sebanyak $3 \%, 4 \%$, 5\%. Mula-mula disiapkan pati sagu sebanyak 10 gram kemudian ditambahkan serbuk kering pelepah kelapa sawit yang telah dibuat sebanyak 5 gram. Setelah itu kemudian ditambahkan gliserol sebanyak 3 grdan sambil menambahkan aquades $250 \mathrm{~mL}$. Setelah itu dilakukan pengadukan dengan strirer dengan kecepatan $4 \mathrm{rpm}$ sambil dipanaskan dengan suhu $120^{\circ} \mathrm{C}$ selama 35 menit hingga larutan membentuk gelatin. Campuran kemudian dicetak dan dikeringkan pada suhu $70^{\circ} \mathrm{C}$ dalam oven selama 14 jam.

\section{Result and Discussion}

\subsection{Hasil Uji Ketebalan (Thickness)}

Pengujian ketebalan film dilakukan di Laboratorium Research and Development PT. Indah Kiat Pulp \& Paper, Perawang. Hasil uji ketebalan dari beberapa variasi konsentrasi kalsium laktat ditunjukkan oleh data berikut.

Tabel 1. Hasil Uji Ketebalan

\begin{tabular}{cccccc}
\hline \multirow{2}{*}{$\begin{array}{c}\text { Kitosan } \\
(\%)\end{array}$} & \multicolumn{2}{c}{ Ketebalan (mm) } & Rata-rata & RPD (\%) & standar \\
\cline { 2 - 3 } & I & II & & & \\
\hline 3 & 0,28 & 0,34 & 0,302 & 4,83 & Maks. $0,25 \mathrm{~mm}$ \\
4 & 0,25 & 0,32 & 0,274 & 6,14 & \\
5 & 0,23 & 0,27 & 0,256 & 4 & \\
\hline
\end{tabular}

Keterangan: Nilai standar baku diperoleh dari Japanese Industrial Standart 2-1707

\subsection{Hasil Uji Kuat Tarik (Tensile)}

Hasil pengujian kuat tarik dari beberapa variasi konsentrasi larutan kitosan 3\%, \$\%, dan 5\% diperoleh hasil sebagai berikut :

Received: November 2021, Accepted : November 2021 - Jurnal Photon Vol.12 No.1

DOI : https://doi.org/10.37859/jp.v12i1.3359 


\section{http://ejurnal.umri.ac.id/index.php}

Tabel 2. Hasil Uji Kuat Tarik (Tensile)

\begin{tabular}{|c|c|c|c|c|c|}
\hline \multirow{2}{*}{$\begin{array}{c}\text { Kitosan } \\
(\%)\end{array}$} & \multicolumn{2}{|c|}{ Kuat Tarik (MPa) } & \multirow{2}{*}{ Rata-rata } & \multirow{2}{*}{ RPD (\%) } & \multirow{2}{*}{ standar } \\
\hline & I & II & & & \\
\hline 3 & 38,92 & 38,01 & 38,465 & 0,591 & \multirow{3}{*}{$24,7-302 \mathrm{MPa}$} \\
\hline 4 & 43,20 & 43,11 & 43,155 & 0,052 & \\
\hline 5 & 51,69 & 51,50 & 51,595 & 0,092 & \\
\hline
\end{tabular}

Keterangan: Nilai standar diperoleh dari SNI $7818: 2014$

3.3 Hasil Uji persen pemanjangan (Elongation)

Hasil pengujian kuat tarik dari beberapa variasi konsentrasi larutan kitosan 3\%, \$\%, dan 5\% diperoleh hasil sebagai berikut.

Tabel 3. Hasil Uji Persen Pemanjangan (Elongation)

\begin{tabular}{|c|c|c|c|c|c|}
\hline \multirow{2}{*}{$\begin{array}{c}\text { Kitosan } \\
(\%)\end{array}$} & \multicolumn{2}{|c|}{ Elongasi (\%) } & \multirow{2}{*}{ Rata-rata } & \multirow{2}{*}{ RPD (\%) } & \multirow{2}{*}{ standar } \\
\hline & I & II & & & \\
\hline 3 & 24,53 & 24,13 & 24,33 & 0,41 & \multirow{3}{*}{$21-220 \%$} \\
\hline 4 & 22,90 & 22,80 & 22,85 & 0,10 & \\
\hline 5 & 21,47 & 21,13 & 21,30 & 0,39 & \\
\hline
\end{tabular}

Keterangan: Nilai standar diperoleh dari SNI $7818: 2014$

\subsection{Hasil Uji kelarutan (Absorbable)}

Hasil pengujian kelarutan dari beberapa variasi konsentrasi larutan kitosan 3\%, \$\%, dan 5\% diperoleh hasil sebagai berikut.

Tabel 4. Hasil Uji Kelarutan (Absorbable)

\begin{tabular}{cc}
\hline $\begin{array}{c}\text { Kitosan } \\
(\%)\end{array}$ & \multicolumn{1}{c}{ Swelling (\%) } \\
\cline { 2 - 2 } 3 & $\mathrm{I}$ \\
\hline 4 & 3,82 \\
5 & 3,07 \\
\hline
\end{tabular}

Received: November 2021, Accepted : November 2021 - Jurnal Photon Vol.12 No.1 
http://ejurnal.umri.ac.id/index.php

\subsection{Hasil uji FTIR (Fourier Transform-Infra Red)}

\subsubsection{Selulosa}

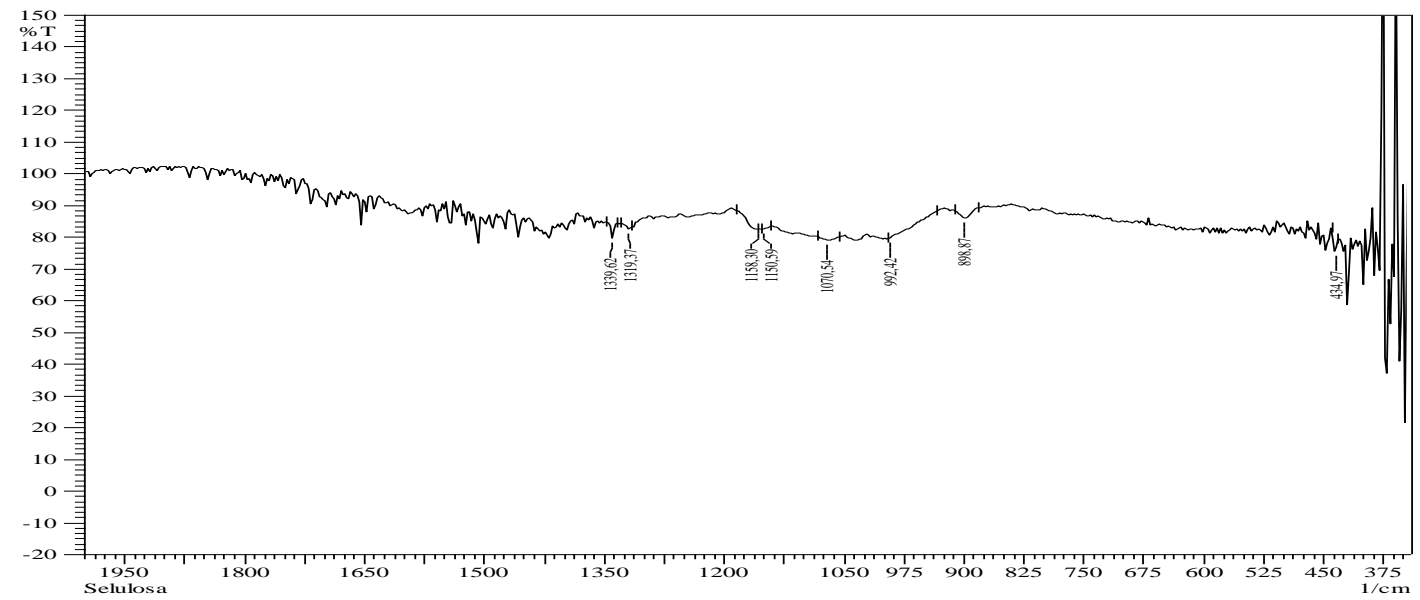

Gambar 1. Spektrum FTIR selulosa

\subsubsection{Pati Sagu}

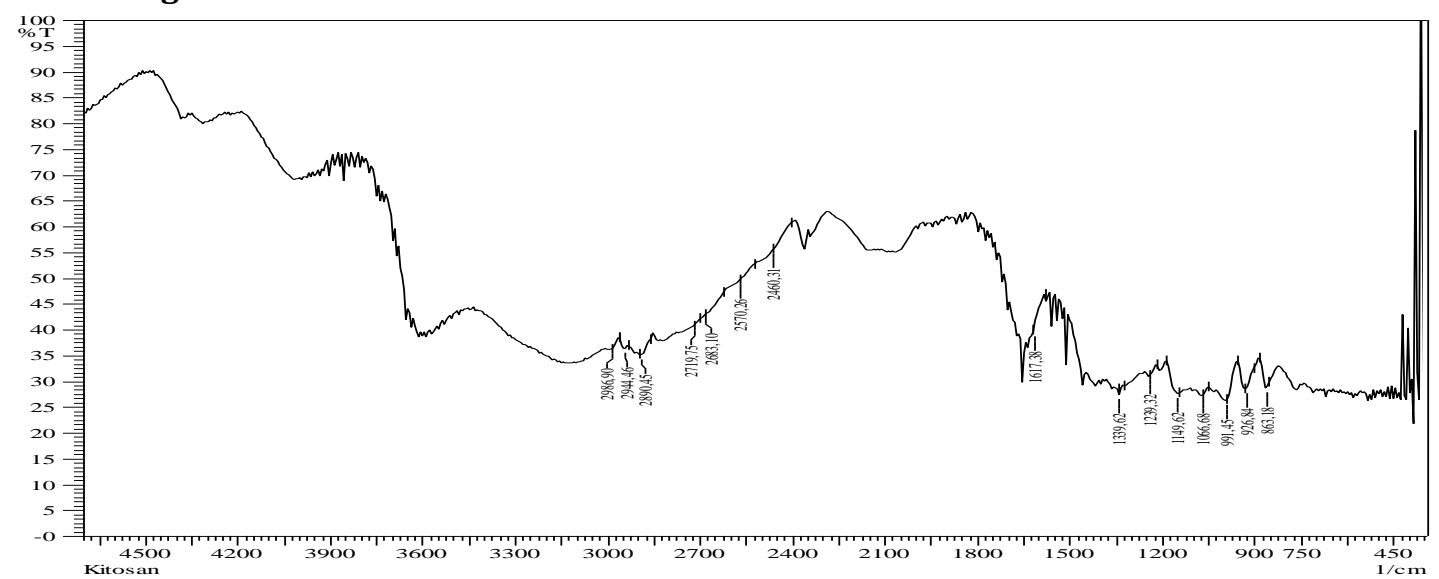

Gambar 2. Spektrum FTIR pati sagu

\section{Conclusion}

Bioplastik berupa lembaran tipis transparan berbahan dasar pati sagu-kitosan berbasis pelepah sawit dan plastizier gliserol telah berhasil dibuat. Hasil pengujian sifat mekaniknya menunjukkan bahwa komposisi terbaik bioplastik adalah pada variasi larutan kitosan 5\% dengan nilai kuat tarik 51,95 Mpa.

\section{Acknowledgement}

Terimakasih diucapkan kepada Ditjen Belmawa Dikti ristek atas pendanaan PKM-RE penelitian ini, Laboratorium FTIR Uniersitas Riau, dan seluruh teman-teman prodi kimia UMRI yang bersedia berpartisipasi dalam penelitian ini.

\section{References}

Ahmad, M., Islamia, J. M. and Ahmed, S. 2015. Adsorption of heavy metal ions : Role of chitosan and cellulose for water treatment.International Journal of Pharmacognosy. 2(6):280-89.

Received: November 2021, Accepted : November 2021 - Jurnal Photon Vol.12 No.1

DOI : https://doi.org/10.37859/jp.v12i1.3359

PHOTON is licensed under a Creative Commons Attribution-ShareAlike 4.0 International License 
Harjanti, R, S. 2014. Kitosan dari Limbah Udang sebagai Bahan Pengawet Ayam Goreng. Jurnal Rekayasa Proses. 8(1):12-19.

Ihwan, R. 2017. Pembuatan Asam Oksalat Dari Pelepah Kelapa Sawit (Elaeis Guineensis) Melalui Reaksi Oksidasi Asam Nitrat. Skripsi. UniversitasSumatra Utara.

Jumadil, K. 2020. Pengaruh Variasi Penambahan Selulosa Pelepah Kelapa Sawit Pada Bioplastik Dari Tepung Maizena Dan Tepung Tapioka. Skripsi. Universitas Muhammdiyah Riau.

Lismawati. 2017. Pengaruh Penambahan Plasticizer Gliserol Terhadap Karakteristik Edible Film Dari Pati Kentang (Solanum Tuberosum L.). Skripsi. Universitas Islam Negri Makassar.

Muhidin, S. L. 2012. Pengaruh Perbedaan Karakteristik Iklim Terhadap Produksi Sagu. Jurnal Agroteknos, 190-194.

Nahir, N. 2017. Pengaruh Penambahan Kitosan Terhadap Karakteristik BioplastikDari Pati Biji Asam (Tamarindus Indica L.). Skripsi. Universitas Islam Negri Makassar.

Novriyani, V., Utami, S, P., dan Bahruddin. 2019. Pembuatan Bioplastik BerbasisPati Sagu Menggunakan Modifikator Asam Sitrat Dengan Microcrystalline Cellulose (MCC) Sebagai Filler dan Sorbitol Sebagai Plasticizer. 6(1):1-5. Pamilia Coniwanti, L. L. 2014. Pembuatan Film Plastik Biodegredabel dari Pati.

Jagung dengan Penambahan Kitosan dan Pemplastis Gliserol. Jurnal Teknik Kimia No.4 Vol. 20 : 22-30.

Putra, R. H. 2020. Pemanfaatan Limbah Pelepah Kelapa Sawit Sebagai Bahan Baku Alternatif Pembuatan Kertas Dengan Metode Kraft. Skripsi. Universitas Muhammadiyah Riau.

Rasli, S. A. M., Ahmad, I., Lazim, A. M., Hamzah, A. 2017. Pengekstarkan dan pencirian selulosa daripada bahan buangan pertanian - pelepah kelapasawit. Malaysian Journal of Analytical Science. 21(5) : 1065-1073.

Ritonga, F. S. 2018 .Bioplastik Dari Pati Biji Durian Berpengisi Kitosan (Menggunakan Pelarut Asam Format Dan Plasticizer Gliserol) Sebagai Plastik Pengemas Minyak. Skripsi. Universitas Sumatera Utara.

Said, A. 2018. Sintesis Plastik Biodegradable Berbahan Komposit Pati Sagu-Kitosan Sisik Ikan Katamba ( Lethrinus lentjam ). Jurnal Inovasi Pendidikan Sains. 9(1):23-30.

Septiosari. A., Latifah., Kusumastuti. E. 2014. Pembuatan dan karakterisasi bioplastik limbah biji mangga dengan penambahan selulosa dan gliserol. Indonesia Journal of Chemical Science, 2(3).

Received: November 2021, Accepted : November 2021 - Jurnal Photon Vol.12 No.1

DOI : https://doi.org/10.37859/jp.v12i1.3359

PHOTON is licensed under a Creative Commons Attribution-ShareAlike 4.0 International License 